\title{
Narrativas da pandemia: de professora experiente à coordenadora pedagógica iniciante de creche
}

\author{
Pademics' Narratives: from skilled teacher to beginning daycare \\ pedagogical coordinator
}

\author{
Dárcia Tostes Costa da Silva \\ Doutora em Educação, Arte e História da Cultura \\ Universidade Presbiteriana Mackenzie - UPM. \\ São Paulo, SP - Brasil. \\ tostes.silva66@gmail.com \\ iD Thatiana Francelino Guedes Pineda \\ Doutoranda em Educação, Arte e História da Cultura \\ Universidade Presbiteriana Mackenzie - UPM. \\ São Paulo, SP - Brasil. \\ th.pineda@gmail.com \\ Maria da Graça Nicoletti Mizukami \\ Doutora em Ciências Humanas \\ Pontifícia Universidade Católica do Rio de Janeiro - PUC \\ Rio de Janeiro, RJ - Brasil. \\ gramizuka@gmail.com
}

\begin{abstract}
Resumo: Este artigo se propõe a analisar, à luz das narrativas, as vivências de uma professora experiente que, durante a pandemia, as sumiu a função de coordenadora pedagógica de creche. Primeiro, atuante com crianças bem pequenas em uma creche da rede pública, na Zona Oeste Paulista; depois, como gestora iniciante com atribuições em uma outra creche, do mesmo município, que atendia somente bebês. Utilizamos como aporte teórico: Clandinin e Connely (2000); Cochran-Smith e Lytle (2015); Dalberg, Moss e Pence (2019) e Oliveira-Formosinho (2009). Por meio das narrativas constatamos que as vivências da professora experiente na educação infantil influenciaram de forma substancial suas ações enquanto gestora iniciante. Compreendemos que a situação da creche física, com suas portas fechadas em virtude da pandemia da COVID19, demonstrou que a presença do professor nunca foi tão necessária.
\end{abstract}

Palavras chave: professor; professor coordenador pedagógico; creche; pandemia.

Abstract: Based on narratives this article aims to analyze experiences of a competent teacher during the pandemic period took the job as a daycare Pedagogical Coordinator. First of all she words with young children in a public daycare facility center at west of São Paulo city. After that she also worked as a manager in another daycare facility center focused on babies in the same city. We have used the following theorical sources: Clandinin e Connely (2000); Cochran-Smith e Lytle (2015); Dalberg, Moss e Pence (2019) e Oliveira-Formosinho (2009). Through narratives we have figured out that the experiences of this teacher in early childhood education substantially influenced her actions as an entry level manager position. Despite conditions of the daycare building keeping doors closed due to COVID-19 pandemic, it was clear that the presence of a teacher in the classroom has never been more necessary.

Key-words: teacher; pedagogical coordinator; daycare; pandemic.

Cite como

(ABNT NBR 6023:2018)

SILVA, Márcia Tostes Costa; PINEDA, Thatiana Francelino Guedes; MIZUKAMI, Maria da Graça Nicoletti. Narrativas da pandemia: de professora experiente à coordenadora pedagógica iniciante de creche. Dialogia, São Paulo, n. 39, p. 1-18, e20623, set./dez. 2021. Disponível em: https://doi.org/10.5585/39.2021.20623.

American Psychological Association (APA)

Silva, M. T. C.; Pineda, T. F. G.; \& Mizukami, M. da. G. N. (2021, set./dez.) Narrativas da pandemia: de professora experiente à coordenadora pedagógica iniciante de creche. Dialogia, São Paulo, 39, p. 1-18, e20623. https://doi.org/10.5585/39.2021.20623. 
Introdução

Este artigo possui duas vertentes, a primeira propõe-se a apresentar as vivências de uma professora experiente atuante em uma sala de referência ${ }^{1}$ com crianças bem pequenas, em uma creche da rede pública, localizada na Zona Oeste da região metropolitana de São Paulo, que durante o período de pandemia, assumiu o cargo de professora coordenadora pedagógica em uma outra creche, do mesmo município, que atendia somente bebês de 4 meses a 1 ano e meio de idade. A segunda vertente é, a partir de suas narrativas, analisar o quanto suas vivências docentes influenciaram suas ações enquanto gestora iniciante, considerando resultados relevantes para os debates que permeiam a Educação de bebês e crianças bem pequenas nas instituições públicas brasileiras.

Nossos interesses concentram-se na experiência particular dessa professora que, além de vivenciar os impactos do fechamento das creches e lidar com a continuidade do seu trabalho em período de quarentena contando com a parceria das famílias devido ao isolamento, assumiu o papel de professora coordenadora pedagógica iniciante e necessitou redirecionar o olhar e ações de sua sala de referência de crianças bem pequenas e suas famílias, para um trabalho mais ampliado que agregava o grupo de professoras e demais funcionários da instituição, acolhendo-os, fortalecendoos e formando-os em um tempo de angústias, incertezas em que o caos social se instaurava.

Tal experiência contribui para o âmbito da pesquisa ao compartilhar sobre a realidade de instituições públicas no período de 2020 e 2021, que vem driblando a instabilidade de posicionamento dos órgãos públicos competentes, os impactos sociais e econômicos das famílias de baixa renda, a falta de estrutura para professores atuarem de suas casas por meio de dispositivos eletrônicos domésticos e particulares, dentre tantos outros impasses que a pandemia revelou. Além da contribuição na pesquisa, a experiência apresentada neste artigo, invoca a reflexão sobre o papel do educar nas creches públicas, tal como o papel dos professores da educação infantil ao participarem efetivamente desse processo.

O contexto aqui retratado é o mesmo de milhares de creches que atendem a crianças de 0 a 3 anos no Brasil, que fecharam suas portas físicas como medida de prevenção da expansão do coronavírus, entretanto, seus professores e gestores tiveram ações incansáveis para atender as crianças e as famílias para além do previsto no início de 2020 no projeto pedagógico anual; em muitas delas, para além do papel da creche tão debatido academicamente. Conforme pesquisa publicada pelo Instituto Península (2020), 74\% dos professores de educação infantil afirmaram ter

\footnotetext{
${ }^{1}$ Na educação infantil, utiliza-se o termo sala de referência e não sala de aula, isto segundo a Resolução $n^{\circ} 5$, de 17 de dezembro de 2009 , art. $8^{\circ}$ inciso VI, p. 3.
} 
mantido contato com as crianças durante a pandemia na oferta de alguma atividade mesmo com a suspensão das aulas presenciais.

Para uma melhor organização, o artigo encontra-se estruturado em três etapas: na primeira, apresenta-se o caminho metodológico, conceitos-chave que permitem elucidar onde nossos pés estão assentados ao debater sobre a educação infantil; na segunda, as narrativas da professora experiente no momento em que vivenciou os impactos da pandemia no exercício docente junto à sua turma de crianças bem pequenas na creche e; na terceira, suas vivências ao assumir a função de professora coordenadora pedagógica, jamais experimentado antes, com o desejo de construir um trabalho de partilha com o grupo de professoras da instituição.

\section{$1 \mathrm{O}$ caminho metodológico e as fundamentações teóricas}

Abordando essa realidade da continuidade de trabalho dos profissionais da educação infantil a escolha metodológica deste trabalho pela análise das narrativas considerou justamente as vivências do período citado contadas pela professora, o que contribuiu com os resultados aqui obtidos. De acordo com Clandinin e Connely (2000, p. 20), a pesquisa narrativa é “[...] uma forma de entender a experiência".

Os dados coletados para este estudo foram obtidos do portfólio da professora, que continha as propostas enviadas às crianças para serem desenvolvidas por sua família e suas respectivas reflexões das devolutivas destas. Também fizeram parte dos instrumentos de pesquisa as falas da professora enviadas por e-mail e Whats $A p p$ às pesquisadoras. Com relação aos dados da professora que se tornara coordenadora, obtivemos acesso as suas narrativas do trabalho com as docentes da creche e suas conversas por Whats $A p p$.

A análise de narrativas tem se tornado cada vez mais presente na formação de professores, seja em atividades de formação inicial e contínua ou como método de investigação e intervenção na pesquisa; tal como reveladora nos estudos de aspectos quanto ao professor, pois o processo de reflexão pedagógica é potencializado ao narrar suas vivências. Rosa Maria de Oliveira afirma que

[...] a narrativa permite, a partir da reflexão que a envolve, construir o conhecimento sobre a docência em uma visão mais ampla, mais profunda, pois nela está o sentimento, a significação, o sentido das histórias trazido por meio da voz, das narrativas de seus protagonistas, os professores (OLIVEIRA, 2011, p. 300).

A afirmativa é que tudo que transcorre em um tempo e em um espaço, pode ser narrado considerando os fatos e os personagens. Em nosso caso, reforçamos que as narrativas tratam de um tempo passado em 2020 e 2021, em uma creche pública localizada na Zona Oeste da região 
metropolitana de São Paulo, envolvendo vivências de uma professora na docência e na gestão em tempos de pandemia, como já citado anteriormente.

Para analisar a narrativa que transcorreu na creche durante o período de pandemia pela professora e depois professora coordenadora pedagógica, utilizamos o termo vivência, que dentro da abordagem Histórico-Cultural, na qual Vigotski é um dos precursores, sustenta a ideia de um indivíduo em sua totalidade, que vincula dialeticamente os aspectos externos e internos, estabelecendo relação com o seu meio. Na vivência cada situação é experimentada de modo único, significativo e rico ao sujeito que passa por ela. Ainda que várias pessoas estejam sujeitas ao mesmo acontecimento, por compartilharem o mesmo meio, cada uma delas sentirá e reagirá de modo diferente à situação (VINHA; WELCMAN, 2010).

As vivências narradas neste artigo ressaltam a infância e a criança como um dos personagens centrais das situações ocorridas em meio à pandemia. Para isso, por infância, a compreendemos como uma construção social e cultural, criada para e pelas crianças de forma conjunta e gerida por relações sociais. Mesmo considerando que a infância se insere em um fato biológico, o modo de concebê-la e como ela acontece, é determinada socialmente (DALBERG; MOSS; PENCE, 2019).

Segundo Dalberg, Moss e Pence (2019), a infância é sempre descrita considerando o tempo, o local e a cultura, com diferenciação de classe, gênero e condições socioeconômicas. Desse modo, é correto afirmar que não existe uma infância natural e nem universal, mas sim muitas infâncias.

A criança na perspectiva de muitas infâncias, é considerada como ator social, participando de modo conjunto da construção e determinação de sua vida. Como ator social, é reconhecida como ser com capacidade de interagir em sociedade e de atribuir sentido às suas ações (SARMENTO; PINTO, 2013; SARMENTO, 2005), possui voz própria que deve ser ouvida e respeitada, envolvida no diálogo e na tomada de decisões (DALBERG; MOSS; PENCE, 2019).

A criança desde o início de sua vida surge como coconstrutora do conhecimento, da cultura e da sua própria identidade. Ela é entendida como sujeito único, complexo e individual, definida por Malaguzzi (1999) como rica em potencial, forte, poderosa e competente. Já nas palavras de Filippini (1999, p. 124) “cada criança é única e protagonista do seu crescimento".

Além da criança, nas narrativas, o professor é um dos personagens retratado. O professor, na vertente de Moss (2011), é concebido como pesquisador, coautor do seu conhecimento e das crianças, sustentador das aprendizagens, das relações e da cultura, questionador das suas próprias imagens de infância, criador de ambientes e situações desafiadoras e aplica-se a constante análise crítica da sua prática em confronto com a teoria. 
Apoiando-se também nas ideias de Cochran-Smith e Lytle (2015) e Mizukami (2020), sustentamos que professores que atuam na primeiríssima infância necessitam ser detentores de uma postura investigativa, referindo-se à posição que adotam na creche frente ao conhecimento e à relação com a própria prática. Professores com postura investigativa, inserem-se em uma pesquisa comum, como sendo um sentido para suas vidas e uma atitude coletiva, em resposta às novas demandas educacionais.

Outro personagem que será retratado nas narrativas é o professor coordenador pedagógico $^{2}$, que, como último conceito ancorado nas ideias de Saitta (1998, p. 114), o compreendemos como "instrumento de programação, estudo, organização, verificação e síntese do projeto pedagógico, que garante o princípio da continuidade da experiência educacional na creche".

A presença do coordenador pedagógico nas creches é bem recente, porém o seu papel é de importância fundamental para garantir e promover três eixos principais que visam romper com a concepção que ainda perdura em algumas creches - o assistencialismo. Esses eixos são: a organização do serviço que envolve a indissociabilidade do cuidar e do educar, o projeto educacional e as competências profissionais dos educadores.

Mesmo com legislações como as Diretrizes e Bases da Educação Nacional (BRASIL, 1996), que asseguram à Educação como direito de todos, inclusive das crianças de 0 a 3 anos em creches ou instituições equivalentes, existe ainda um longo caminho a ser percorrido para que esse direito seja garantido não apenas em atenção às necessidades de trabalho das famílias, mas da creche enquanto espaço privilegiado para afirmar o direito da criança.

Ao coordenador pedagógico cabe a tarefa de coordenar conjuntamente com seus professores um trabalho que vise elaborar e desenvolver um projeto pedagógico no qual a criança seja o "centro do planejamento curricular" (BRASIL, 2009, n.p.), rompendo com práticas espontâneas, individuais, improvisadas e não-coordenadas. Assim, o coordenador pedagógico nas palavras de Gouveia e Placco (2013, p. 70) assume o papel de "um articulador de aprendizagem" por meio de observação atenta conduzida à ação, isto porque na perspectiva de Dewey (1976, p. 66-67), “[...] só observação não é o bastante. Temos de compreender a significação do que vemos, ouvimos e tocamos. Essa significação consiste nas consequências, que resultam de nossa ação, em face e à luz dos sinais que vemos, ouvimos ou tocamos".

\footnotetext{
${ }^{2}$ Professor coordenador pedagógico é a nomenclatura utilizada para designar esse cargo na gestão no município onde a professora colaboradora do estudo atua.
} 
A observação esperada da coordenação pedagógica é a que desencadeia para o treinamento contínuo por meio do desenvolvimento profissional docente, ocorrido no chão escola, com momentos de estudos, espaços para trocas de experiências, construção de teorias locais, discussões e diálogos sobre as problemáticas do dia a dia da instituição e que coloque o professor como elemento central da sua formação (CANÁRIO, 1998; OLIVEIRA-FORMOSINHO, 2009; MARCELO, 2009).

É requerido também que este exerça o papel de acompanhar os professores na atuação com as crianças, nas elaborações das propostas de experiências, nos projetos das salas e da escola, na construção e organização dos espaços da creche.

Filippini (1999) ao descrever o papel do pedagogista em Reggio Emilia, cria para nós uma importante correlação com o trabalho do coordenador pedagógico e propõe pontos a se considerar nessa função, como: engajar-se em um intercâmbio contínuo de informações sobre o interno da escola, atualizar-se das teorias e práticas, das legislações e demais temas que dizem respeito ao trabalho educacional; interagir com os adultos para implantar as ideias da instituição; trabalhar com os docentes identificando novas experiências e necessidades de formação em serviço e; estar disponível para assessorar os professores no trato diário pessoal com as famílias. Por fim, o coordenador "tem a tarefa complexa e multifacetada de promover um crescimento cultural e social dos sistemas para as crianças pequenas" (FILIPPINI, 1999, p. 127).

Feitas estas importantes conceituações que marcam o lugar em que nossos pés estão fincados, compartilhamos as vivências da professora de creche e da mesma professora que se tornou professora coordenadora pedagógica em meio à quarentena.

\section{Vivências na pandemia de uma professora experiente desafiada pela educação remota} para crianças bem pequenas

Ressaltamos antes mesmo de apresentarmos a narrativa da professora que, como já esclarecido neste texto, compreendemos a criança como um sujeito potente, ator social e protagonista, pois enquanto estudiosas da infância, não validamos a transposição da Educação de bebês, de crianças bem pequenas e pequenas para a formatação de Educação à distância. Fazemos isso inclusive, validadas pela LDB n 9.394/96 (BRASIL, 1996) que em seus artigos 29, 30 e 31, ao definir a educação infantil, não menciona o ensino a distância para essa etapa da Educação, enquanto a faz para o ensino fundamental ao determinar: Art. 32 - parágrafo $4^{\circ}$ “"...] sendo o ensino a distância utilizado como complementação da aprendizagem ou em situações emergenciais" (BRASIL, 1996). 
E, ainda, por considerar a criança como sujeito histórico e de direitos como apontam as Diretrizes Curriculares Nacionais de Educação Infantil (BRASIL, 2009), que de modo lúdico aprende e se desenvolve pelas interações com os objetos, meios e pessoas. Sujeito que está imerso em um ambiente científico, produz cultura e busca desvelar o mundo moída de curiosidade.

Embora cientes que na educação infantil não damos aulas para as crianças, mas promovemos por meio da intencionalidade pedagógica, de um olhar atento e uma escuta sensível, experiências que coloquem a criança em constantes interações e, por meio do conhecimento advindo dela própria, pelas suas experiências e saberes, ampliamos com os conhecimentos que fazem parte do patrimônio cultural, artístico, ambiental, científico e tecnológico, a fim de possibilitar o seu desenvolvimento integral (BRASIL, 2009). Infelizmente o termo aula ainda aparece colado na educação infantil, como uma herança a ser vencida, na qual está a serviço de preparar as crianças para o ensino fundamental.

A ideia do artigo está longe de trazer receitas, modelos de práticas pedagógicas ou de avaliar como certas ou erradas as posturas adotadas frente à implantação das aulas remotas para crianças bem pequenas. Entretanto, apoiando-se nas palavras de Fochi e Coutinho (2020) "conhecer algumas experiências nos atalham em alguns caminhos". Seu pensamento permite que possamos discutir, conhecer e ressignificar novas experiências, sem a intenção de transplantá-las para a nossa realidade educacional.

A professora que compartilhou suas vivências para este artigo, atua na educação infantil da rede pública há quinze anos, sendo treze deles atuando em creche e dois anos com pré-escola. Sua narrativa inicia apresentando o cenário dos primeiros momentos do ano letivo de 2020 sem a consideração dos acontecimentos que envolviam a COVID-19 em outros países.

\footnotetext{
Iniciamos o ano de 2020, no dia 08 de fevereiro, com muitas expectativas com relação a nossa sala de referência, que fora composta por 32 crianças, todas chegando com os olhinhos brilhantes. Alguns marejados de lágrimas pelo medo e dor da separação momentânea de sua família, outros, o brilho era de pura curiosidade e encantamento com os brinquedos e materiais organizados estrategicamente no espaço da sala. Cientes das múltiplas infâncias que estavam diante dos nossos olhos, tal postura nos permitiu que cada dia em nossa sala de referência se tornasse um encontro (Professora participante).
}

Vemos que a professora discorre de momentos corriqueiros de acolhimento das crianças pequenas e, ao percebê-las em sua singularidade frente ao novo ambiente reforça a compreensão da criança como ator social, um sujeito com voz e competente (SARMENTO; PINTO, 2013; SARMENTO, 2005; DALBERG; MOSS; PENCE, 2019), que ao adentrar nesse espaço é modificada e o modifica. A ciência do reconhecimento das múltiplas infâncias ao destacar o papel do professor em sua fala, nos confirma a sua concepção de criança e nos permite analisar seu 
entendimento pelo encontro diário com elas, o que nos leva à definição do pensador lituano Emmanuel Levinas (apud DALBERG; MOSS; PENCE, 2019, p. 57) como o reconhecimento que o outro é "único e não permutável” e a forma de nos relacionarmos deveria considerar o "outro concreto". Nessa ideia está inserida um olhar atento para repudiar qualquer forma de discriminação, opressão, rejeição a um trabalho com atividades com objetivos pré-estabelecidos.

Tais compreensões são percebidas também na continuidade da narrativa da professora ao tratar sobre as propostas ofertadas no momento de acolhimento ao diferenciar experiência e atividade para as crianças.

\begin{abstract}
Utilizamos na creche o termo experiência e não atividades, porque ao tomar como referência o primeiro termo, supõe-se que as crianças como seres competentes, ativos e ávidos por aprender, mergulharão de forma inteira nas ações, manipulando, explorando, sem a necessidade de serem direcionados pelos adultos. Nesse caminho seguido, cabia espaço para o novo, o encantamento, o assombro, o inacabado, assim, o primeiro movimento foi o de conhecer as crianças, suas necessidades, interesses e curiosidades para a partir daí, junto com a equipe da sala e das crianças, partindo das pistas que elas nos ofertavam, construirmos um trabalho no coletivo (Professora participante).
\end{abstract}

O entendimento sobre o termo experiência narrado pela professora, nos remete aos pressupostos de que a ação não se desenvolve mecanicamente como pressupõe o termo atividade, pois conforme Dewey (1976, p. 26) “[...] toda experiência modifica quem a faz e por ela passa e a modificação afeta, quer o queiramos ou não, a qualidade das experiências subsequentes, pois é outra, de algum modo, a pessoa que vai passar por essas novas experiências". De fato, a experiência envolve o processo de transformação e, no caso da criança que está em constante desenvolvimento, considerarmos as ações pedagógicas como tal, é fundamental tanto no planejamento quanto na prática do professor.

Dando sequência à fala da professora, ela comenta o período de adaptação das crianças anterior às mudanças de percursos necessários pela determinação de quarentena. Vejamos:

\footnotetext{
o processo de adaptação com a nossa sala fora bem desenvolvido e as crianças demonstravam grande alegria e prazer a cada novo dia que chegavam à creche. Até que, em meados de março, começaram os rumores de uma nova doença que atingia o mundo, denominada COVID-19. Logo surgiu o primeiro infectado no Brasil e rapidamente a doença começou a se espalhar ganhando em todo o mundo a dimensão de pandemia (Professora participante).
}

A situação enfrentada pela professora foi a mesma de milhares de profissionais que foram impactados com a veiculação de notícias sobre o agravamento da situação em diferentes países e as repercussões no território brasileiro. O cenário com o aumento de infectados, a ocorrência de mortalidade e a lentidão do Governo Federal em adotar um programa com medidas a fim de lidar 
com a pandemia, impulsionou governadores a iniciarem as ações solitárias e isoladas, como a do governador de São Paulo João Doria, que por meio do Decreto nº 64.879 de 20 de março de $2020^{3}$, suspendeu as aulas presenciais em todo o Estado de São Paulo até 30 de abril de 2020, devido a infecção humana pelo novo coronavírus.

Como ação subsequente, o Conselho Nacional de Educação (CNE) pelo Parecer CNE/CP $5 / 2020$ prescreveu normas excepcionais que autorizavam às instituições educacionais a ofertarem atividades não presenciais (BRASIL, 2020). Com essa medida tornou-se necessário reorganizar o calendário escolar e, no dia 28 de abril de 2020, foi instituída a Medida Provisória - MP no 934/2020, cuja finalidade foi dispensar a obrigatoriedade do mínimo de dias letivos para o ano de 2020, ficando mantida a carga horária mínima de 800 horas aula/ano (BRASIL, 2020). Convém ressaltar que os profissionais da Educação receberam essas normas como algo bastante confuso.

Vejamos esse momento nas palavras da professora:

\begin{abstract}
Era uma sexta-feira quando recebemos a notícia que, a partir de segunda-feira próxima, a creche ficaria fechada. Foi um momento assustador, não sabíamos o que estaria por vir. As pessoas no interior da instituição ficaram apavoradas, havia muitas providências a serem tomadas, dentre elas avisar as famílias do fechamento das portas da creche no início da semana seguinte. Todos imaginávamos que passaria logo e em breve retornaríamos as nossas atividades normais na escola (Professora participante).
\end{abstract}

Lidar com as diversas orientações, a instabilidade de decisões e o desconhecimento da doença, levou cada instituição a tomar medidas possíveis para atender sua comunidade escolar. Uma das medidas foi a opção pelo contato com as famílias contando com os recursos tecnológicos digitais disponíveis.

\begin{abstract}
Passadas umas duas semanas, recebemos a orientação da Secretaria de Educação que as famílias receberiam pelo Whats $A p p$ e site criado pelas escolas, as propostas a serem realizadas com as crianças em suas casas, tal como eram preparadas para a formatação presencial. Inicialmente, toda a educação infantil do município foi orientada a criar o Whats App Business, no qual apenas os gestores teriam acesso realizando a ponte com as famílias e a creche, enviando as propostas que os professores haviam preparado para a semana (Professora Participante).
\end{abstract}

Neste trecho podemos perceber algo que foi um tanto comum nas escolas públicas e particulares; uma forma rápida e de fácil acesso para todos, inclusive para os pais que já tinham conhecimento do aplicativo por uso pessoal. Porém, uma questão que ressaltamos do uso desta forma de comunicação, está no tempo disponível excessivo, muito além do horário previsto no contrato de trabalho dos profissionais.

\footnotetext{
${ }^{3}$ Assembleia Legislativa do Estado de são Paulo. DECRETO Nº 64.879, DE 20 DE MARÇO DE 2020. Reconhece o estado de calamidade pública, decorrente da pandemia do COVID-19, que atinge o Estado de São Paulo, e dá providências correlatas.
} 
Outra questão refere-se aos desafios encontrados de forma súbita em março, exigindo ações emergentes nas escolas além de criar um canal de comunicação com as famílias: a falta de preparo e vivência frente às situações impostas, professores e gestores não sabiam como reagir.

Infelizmente, devido à falta de atenção dada às vozes e os clamores dos professores de um modo geral, a vivência de uma situação inusitada no mundo e a inapropriação dos setores que coordenavam a Educação no país, em cogitar e adotar a realização de aulas de forma remota para crianças bem pequenas, fez com que muitos de nós, demorássemos um certo tempo para perceber e agir de modo a ajustar as nossas propostas para o contexto da casa da criança. Isto significava utilizar a rotina, os materiais, as tarefas domésticas e as relações familiares, como conteúdo curricular da educação infantil. Para muitos professores ainda presos em atividades, controladas com começo, meio e resultado esperado, isso parecia ser uma tarefa árdua e inconcebível (Professora participante).

Apoiando-se no pensamento de Shön (1997) no refletir sobre a reflexão-na-ação, caracterizado pelo momento em que as professoras passam a refletir sobre as propostas enviadas às famílias e a ausência de devolutivas, elas pensam no que aconteceu e reformulam suas ações como abaixo narrado:

Com queixas que as famílias não realizavam as propostas enviadas para casa e não interagiam nos grupos das salas, as professoras da nossa creche perceberam que atuando desta forma estávamos criando um abismo entre as crianças e nós e, contrariávamos um dos princípios invioláveis da creche, enquanto fonte de oportunidade para as crianças no sentido de socializar, dialogar e trocar. Assim, em diálogo com a gestão da escola, decidimos interagir com as crianças, postando diretamente nos grupos da sala as experiências pensadas para as crianças. Passamos a contar histórias, cantar músicas diárias com as crianças tal qual fazíamos em sala, chamávamos as crianças pelos nomes e dávamos espaços para que conversassem conosco (Professora participante).

Podemos analisar que a escolha pela ferramenta digital de comunicação com as famílias, não foi o maior dos problemas, mas sim o formato de como as propostas dos professores seriam recebidas e principalmente o aproveitamento delas pelas crianças. A situação nunca vivenciada de ambos os lados, creche e família, evidenciou um período de testagem de ações pedagógicas para as crianças pequenas. Nesse momento, a continuidade da fala da professora, nos traz considerações sobre a busca de formação para contribuir com as escolhas.

Se por um lado, nós professores estávamos preocupados em manter o vínculo afetivo com as crianças e as famílias, nos aperfeiçoando por meio de cursos de forma on-line e procurando aprender com outras experiências em como tornar esse momento atingível aos pequenos, do outro lado os sistemas de Educação ocupavam-se em cobrar dos docentes de modo percentual a participação das famílias nos grupos de Whats App e que as postagens de atividades fossem produções elaboradas com vídeos, carregadas de imagens e efeitos atrativos aos olhos dos adultos, sem considerar sua significação às crianças e que tal oferta exigia delas um longo tempo frente às telas, fato que contraria as orientações dos pediatras (Professora participante). 
Apesar do nosso foco na formação docente neste trecho da narrativa, não podemos ignorar o destaque pelos interesses dos gestores municipais com os dados estatísticos e a jogada de responsabilidade para as professoras em lidar com a produção de materiais não conhecidos. A busca individual pela formação foi crescente entre os professores no período de pandemia. Sobre esse momento a professora destaca também que:

\begin{abstract}
Inicialmente, este foi um momento de muita ansiedade, angústia e inquietude, não estávamos preparadas para trabalhar de modo remoto com as crianças, não dominávamos recursos tecnológicos e devido à falta de conhecimento e sensibilidade daqueles que dirigiam o sistema educacional, houve inicialmente a orientação que os professores da creche e da pré-escola mantivessem o mesmo formato de planilhas contento o plano de aula presencial para envio de sugestões e orientações de atividades a serem utilizadas com as crianças por suas famílias (Professora participante).
\end{abstract}

Com o avanço da COVID-19, houve a necessidade do prolongamento da quarentena e as Secretarias de Educação, especialmente aquelas pertencentes ao Estado de São Paulo, percebendo a precariedade de formação tecnológica dos seus professores, iniciaram uma formação intensiva on-line para todos os docentes, conforme relatado pela professora.

Outro ponto que podemos analisar na narrativa da professora foi a preocupação com as famílias durante todo o momento de atividades não presenciais. Afinal, não era apenas a vida dos professores e das crianças que haviam sofrido com o impacto da pandemia, mas de toda uma sociedade que precisou buscar estratégias para uma nova realidade. Dando sequência ao trecho da fala da professora destacado acima, vemos as suas considerações:

Este foi um tempo de muitas queixas das professoras da creche e um silêncio no grupo de Whats $A p p$ da sala. Começamos a perceber que as famílias não davam retorno da aplicação das propostas com seus filhos porque estavam mergulhadas em suas demandas, tentando ajustar a rotina da casa, muitas delas o pai ou a mãe, ou ambos, passaram a trabalhar em casa, alguns precisaram arrumar uma pessoa para cuidar do seu filho, enfim, havia um caos na vida das famílias. Reorganizamos a forma de envio de orientações às famílias, a casa passou a ser o laboratório da criança, a rotina, as vivências, as tarefas domésticas passaram a ser consideradas como o conteúdo do currículo da Educação neste momento. Atendíamos as solicitações de algumas famílias em conversar com as crianças por áudios ou vídeo, porque pediam para voltar à creche e diziam que os pais não queriam levá-las (Professora participante).

Há décadas vem se debatendo sobre a parceria da família e escola visando contribuir com o desenvolvimento e aprendizagem das crianças pequenas. Nesse período vivenciado entre 2020 e 2021, essa questão foi mais que emergencial de diálogo, pois sem ela, seria inviável qualquer proposta pedagógica chegar às crianças.

Durante o período de isolamento social, com as portas das creches fechadas para as atividades presenciais, foi possível perceber de maneira crescente professores pesquisadores, com 
postura investigativa, coautores do seu conhecimento e das crianças, sustentadores das relações e da cultura infantil, questionadores das suas próprias imagens de infância e apoiadores da aprendizagem de cada criança apesar das situações controversas (MOSS, 2011; COCHRANSMITH; LYTLE, 2015; MIZUKAMI, 2020).

As palavras finais da professora ocupando essa função, ao sintetizar esse período, são carregadas de sentimentos docentes e reflexões: “Apesar de todo medo e insegurança sentidos, nos esforçamos para fazermos presentes na vida das crianças, para que soubessem que estávamos vivas e que a escola não fora engolida por um buraco aberto no chão" (Professora participante). A preocupação central é a relação professor-criança frente às possibilidades e desafios. Acrescenta ainda que: "Este foi um tempo novo, assustador e inédito em que foi possível repensar e reafirmar nossos valores, conceitos e propósito para com a Educação de crianças bem pequenas" (Professora participante).

Sua fala nos traz à memória reflexões de Freire, que não podemos ficar amarrados e paralisados diante dos entraves e deixar de fazer o que é possível e o que nos compete, porque

o que não podemos como seres imaginativos e curiosos, é parar de aprender e de buscar, de pesquisar a razão de ser das coisas. Não podemos existir sem nos interrogar sobre o amanhã, sobre o que virá, a favor de quem, contra quem virá; sem nos interrogar em torno de como fazer concreto o "inédito viável" demandando de nós a luta por ele (FREIRE, 1992, p. 50).

\section{Vivências de uma professora que se tornou gestora em plena pandemia}

Como dito na introdução deste artigo, a mesma professora que contribuiu com suas narrativas das experiências tidas em sua sala de referência com crianças bem pequenas, é a que, em plena pandemia, assumiu, pela primeira vez, o cargo de coordenadora pedagógica de outra creche no mesmo município de São Paulo.

Alicerçada em suas convicções teóricas de que um coordenador pedagógico necessita ser um "um articulador de aprendizagem" (GOUVEIA; PLACCO, 2013, p. 70), que deva considerar como papel principal o de atuar de maneira colaborativa na formação dos professores e da equipe institucional e ainda encharcada pela vasta experiência como docente, assim nos narrou a professora coordenadora pedagógica:

\footnotetext{
Nutrida pelas vivências da docência, entrei na coordenação pedagógica com um vasto repertório de situações sentidas durante a caminhada na sala de referência, na escola e com minhas companheiras de profissão, mas acima de tudo existia o desejo de contribuir com essa parcela da Educação e não repetir os modelos de coordenação que não contemplavam a minha concepção de Educação de Escola da Infância. Iniciamos o trabalho movidas pelo respeito, consideração da importância do trabalho do professor e pelo reconhecimento deste como uma pessoa completa e singular (Coordenadora pedagógica participante).
} 
A formação centrada no chão da escola, sob a perspectiva do desenvolvimento profissional docente (CANÁRIO, 1998; OLIVEIRA-FORMOSINHO, 2009; MARCELO, 2009), com reuniões semanais para estudo, diálogo, trocas de experiências, ajustes de rotas e ouvir atentamente as vozes das professoras, foi o caminho escolhido para coordenar conjuntamente um trabalho para a elaboração do projeto pedagógico em um momento peculiar. Esse, o projeto, considerou que a criança se constitui como "centro do planejamento curricular" (BRASIL, 2009, n.p.), rompendo com práticas inadequadas para a Educação à distância. Assim nos aponta que:

Foram necessários alguns diálogos, momentos de estudos com as professoras e
orientações de suas propostas de experiências para o envio às famílias utilizarem com as
crianças. Nestes encontros começamos o trabalho de descontruir algumas terminologias
que historicamente continuam menosprezando o potencial da criança, o seu
protagonismo, a sua criação. Palavras como atividade, mostrar para a criança como
realizar a atividade, objetivo, que o bebê entra na vida como folha em branco, que ele é
frágil, carimbar pés e mãos (Coordenadora pedagógica participante).

A coordenadora ao ler as propostas de trabalho das professoras ouviu atentamente suas queixas pela ausência de devolutivas das famílias no grupo do Whats App e observou com a intenção de atuar sobre o observado (DEWEY, 1976). Sobre isso, a professora coordenadora expôs a seguinte reflexão:

Desde o início do trabalho remoto as professoras não tiveram contato com as famílias pelo Whats $A p p$ do grupo, elas preparavam as atividades e enviavam para o diretor e este mandava para os pais das crianças da sala correspondente. Percebemos que esta prática afastava as famílias das professoras e que o conteúdo enviado para casa, exigia que os pais preparassem ou construíssem materiais para desenvolver as atividades com as crianças, existia ainda, por parte de algumas professoras a preocupação do ensino de cores e muitas delas compreendiam como necessário solicitar ao adulto que se ocupava da criança que guiasse ou demonstrasse ao bebê como realizar as propostas (Coordenadora pedagógica participante).

Com base nessa observação direcionada para a ação, a professora coordenadora nos contou que passou a atuar no acompanhamento da elaboração das propostas de experiências que as professoras realizavam, propunha sugestões e orientava com devolutivas das propostas enviadas à coordenação antes de serem encaminhadas às famílias.

\footnotetext{
Iniciamos um trabalho contínuo, por nós já experimentado na docência, que fora o de sinalizar às professoras que a casa da criança especialmente neste momento de quarentena é o seu ateliê, o seu mundo de experiência e, portanto, era de lá que deveriam emanar as aprendizagens e as aquisições de conhecimentos, assim, as professoras foram orientadas a olhar para a casa do bebê como fonte e repertório para suas propostas de experiências. Esta assertiva foi confirmada pelas famílias, pois em reuniões on-line realizadas entre famílias-escola, demonstraram apreciação por esse tipo de propostas e passaram a responder positivamente postando fotos, vídeos e dando depoimento que as crianças ficavam felizes em participar da rotina do lar e os pais aprovaram receber orientações sobre como tornar ações do cotidiano como comer, sono, banho, troca de fralda em momentos lúdicos, afetivos e ricos para aprendizagens (Coordenadora pedagógica participante).
} 
Outro ponto primordial exercido pela professora coordenadora que surge validado por Filippini (1999), foi o de criar um intercâmbio contínuo de informações sobre o interno da escola, atualizar-se das teorias e práticas, das legislações e demais temas que dizem respeito ao trabalho educacional. Além das professoras serem contempladas com essas temáticas, elas passaram a ser canais de comunicação desses conhecimentos por meio de contatos semanais com as ADHs (Agente de Desenvolvimento Humano, tratando-se de 4 adultos que auxiliam as professoras em cada sala da creche, por se tratar de bebês).

\footnotetext{
Para estreitar a parceria entre as professoras e as ADHS de suas salas foram desenvolvidas reuniões on-line semanais, nas quais as professoras coordenavam os encontros com estudos, diálogos, ajuste do trabalho com as crianças e momentos de escuta (Coordenadora pedagógica participante).
}

Essa ideia de agregar as pessoas da creche para que todos se sintam pertencentes e corresponsáveis pela Educação das crianças aparece respaldada por Saitta (1998) e Filippini (1999), no cuidado com os adultos da creche, ninguém poderia ficar de fora as ADHs, pessoal da cozinha, lavanderia e limpeza todos foram alvos de formação, escuta e acolhimento em forma de reuniões on-line.

Com base nessas narrativas é possível afirmar que o coordenador pedagógico é o elementochave para promover a melhoria da qualidade na instituição. Ele pode ser comparado metaforicamente com o fio do colar de missangas de Mia Souto "a missanga [sic], todos a veem. Ninguém nota o fio que, em colar vistoso, vai compondo as missangas [sic]" (MIA SOUTO, 2004 apud GOUVEIA; PLACCO, 2013, p. 69), é a formação dos professores que resulta em boas práticas e essa, por sua vez, nas aprendizagens das crianças, as missangas, mas quem une, sustenta e forma esta bela configuração do colar é o coordenador, o fio.

Entende-se que a parceria com os professores e com a equipe institucional é condição primeira para o êxito no trabalho do coordenador. Suas ações devem ser interligadas envolvendo todas as pessoas que habitam no local, desenvolvendo uma postura respeitosa, de diálogo com todos, reflexiva e de escuta atenta para que possa ser capaz de concretizar bons momentos de formações, criar espaço de escuta, construir conjuntamente e articular o projeto político pedagógico da instituição. A finalidade é promover o desenvolvimento e aprendizagem de suas crianças e, durante o processo, sentir-se recompensado com o cumprimento de sua função como narrado pela professora coordenadora pedagógica: 
Essas ações acompanhadas e orientadas por nós enriqueceram, definiram e ressignificaram a importância do trabalho da coordenação pedagógica, para garantir que mesmo a creche estando de portas fechadas não se distancie das crianças e dos adultos que a ela pertencem (Coordenadora pedagógica participante).

A análise das narrativas nos permite perceber os impasses enfrentados com a transição dos cargos (de professora para coordenadora pedagógica) em um momento de desafios intensos para a Educação, sobretudo para as creches, que atuaram na pandemia com bebês e crianças pequenas a distância. Vemos que as vivências tidas anteriormente, como professora, foram ressignificadas, tornaram-se experiências que transformaram suas ações enquanto coordenadora pedagógica. Suas palavras nos apontam para diálogos mais realistas, mais condizentes com as situações impostas na educação infantil a fim de garantir um desenvolvimento e aprendizagem da melhor qualidade.

\section{Considerações finais}

Neste estudo, constatamos por meio das narrativas que, as vivências da professora experiente na educação infantil, influenciaram de forma substancial suas ações enquanto gestora iniciante. Entretanto, chamamos atenção de que, o momento em que essa transição de funções ocorreu, foi ainda mais relevante visto que os desafios e impasses comuns aos professores nos primeiros momentos da pandemia, para esta coordenadora, impactou positivamente para nortear novas propostas em um ambiente em que se ansiava por ações formativas e conduções das ações na equipe.

Compreendemos que a situação da creche física, com suas portas fechadas em virtude da pandemia pela COVID-19, ensinou-nos lições preciosas, uma delas foi que a presença do professor nunca fora tão necessária e requisitada pelas famílias. As orientações pensadas a partir da casa do bebê ajudaram às famílias a lidar com a ansiedade de organizar a rotina do adulto incluindo a criança, tornou-se necessário organizar: a alimentação, a regulação do horário do sono, o banho e a troca de forma afetiva e lúdica.

Se por um lado houve inquietações por parte das famílias sobre com quem deixar seus filhos ou como realizar seus trabalhos em casa junto com a criança, pois, muito embora a presença e a função da creche é a de garantir um espaço para que a criança se desenvolva de modo integral e aprenda de forma significativa, para a grande maioria das famílias ainda é o lugar de deixar seus filhos seguros para que possam trabalhar. Por outro lado, esse foi um tempo em que os pais tiveram a oportunidade de orientados pelas professoras e gestão escolar, acompanhar o desenvolvimento e aprendizagem de seus bebês, ficando surpresos com o que eles eram capazes de realizar sozinhos. 
Entendemos que a lição maior da pandemia exigindo o fechamento das escolas é que precisamos rever o nosso modo de Educar os bebês e as crianças bem pequenas, de nos relacionarmos com as famílias criando vínculos afetivos e estabelecendo parcerias. Lição essa que tem sido tema de debates por anos e que somente agora teve uma maior visibilidade não apenas de pesquisadores da área, mas de todos os profissionais, famílias e a sociedade no geral. E, por fim reconhecer que quem deve definir o que ensinar, como e quando, são os professores; sendo assim, eles precisam participar das mesas de discussões e negociações sobre o futuro da Educação dos pequenos em qualquer situação que se apresente.

\section{Referências}

BRASIL. Lei no 9.394, de 20 de dezembro de 1996. Estabelece as diretrizes e bases da educação nacional. Brasília: Casa Civil, 1996.

BRASIL. Resolução ñ 5, de 17 de dezembro de 2009. Fixa as Diretrizes Curriculares Nacionais para a Educação. Ministério da Educação Conselho Nacional de Educação Câmara de Educação Básica. Brasília, 2009.

BRASIL. Conselho Nacional de Educação. Parecer/CP N 5/2020. Reorganização do Calendário Escolar, dispõe sobre a reorganização do Calendário Escolar em Razão da Pandemia da COVID19. 2021. Disponível em:

http:/ / portal.mec.gov.br/index.php?option=com_docman\&view=download\&alias $=145011$ pcp005-20\&category_slug=marco-2020-pdf\&Itemid=30192. Acesso em: 23 mar. 2021.

BRASIL. Medida Provisória - MP n 934/2020. Normas excepcionais sobre a duração do ano letivo 2020. Disponível em: https://www.in.gov.br/en/web/dou/-/medida-provisoria-n-934-de-1-deabril-de-2020-250710591. Acesso em: 24 mar. 2021.

CANÁRIO, R. A escola: o lugar onde os professores aprendem. Psicologia da Educação. São Paulo, n. 6. p. 9-27, 1998.

CLANDININ, D. J.; CONNELLY, F. M. Narrative inquiry: experience and story in qualitative research. San Francisco: Jossey-Bass, 2000.

COCHRAN-SMITH, M; LYTLE, S. L. Relationships of Knowledge and practice: teacher learning in communities. Review of Research in Education, Vol. 24 (1999), 02 nov. 2015, p. 249-305. Disponível em:

https://www.academia.edu/4746288/Chapter_8_Relationships_of_Knowledge_and_Practice_T eacher_Learning_in_Communities. Acesso em: 7 de mar. 2020.

DAHLBERG, G.; MOSS, P.; PENCE, A. Qualidade na Educação da primeira infância: perspectivas pós-modernas. Tradução: Magda França Lopes. Porto Alegre: Penso, 2019, p. 9-85.

DEWEY, J. 1859-1952. Experiência e educação. Tradução de Anísio Teixeira. 2 ed. São Paulo: Ed. Nacional, 1976, p. 65-72. 
FILIPPINI, T. O papel do pedagogista. In: EDWARDS, C.; GANDINI, L.; FORMAN, G. (orgs.). As cem linguagens da criança: a abordagem de Reggio Emilia na educação da primeira infância. Trad. Dayse Batista. Porto Alegre: Editora Artes Médicas Sul Ltda, 1999, p.123-127.

FOCHI, P.; COUTINHO, A. Live - Perspectivas para o retorno na Educação Infantil. 22 de maio de 2020. Disponível em: https://www.youtube.com/watch?v=RvU9bUQG36A. Acesso em: 22 maio 2021.

FREIRE, P. Pedagogia da Esperança: Um encontro com a Pedagogia do Oprimido. Rio de Janeiro: Paz e Terra, 1992.

GOUVEIA, B.; PLACCO, V. M. N. de. A formação permanente, o papel do coordenador pedagógico e a rede colaborativa. In: ALMEIDA, L. R.; PLACCO, V. M. N. (Org.). O coordenador pedagógico e a formação centrada na escola. São Paulo: Edições Loyola, 2013.

INSTITUTO PENÍNSULA. Sentimento e percepção dos professores brasileiros nos diferentes estágios do Coronavirus no Brasil. Março de 2020. Disponível em: https:/ / institutopeninsula.org.br/wpcontent/uploads/2020/05/Pulso-Covid-19_-Instituto-Peni\%CC\%81nsula.pdf. Acesso em: 14 junho 2021.

MALAGUZZI, L. História, Ideias e Filosofia Básica. In: EDWARDS, C.; GANDINI, L.; FORMAN, G. (orgs.). As cem linguagens da criança: a abordagem de Reggio Emilia na educação da primeira infância. Trad. Dayse Batista. Porto Alegre: Editora Artes Médicas Sul Ltda, 1999, p. 59104.

MARCELO, C. Desenvolvimento Profissional Docente: passado e futuro. Sísifo. Revista de Ciências da Educação, Lisboa, n. 8, p. 7-22, jan/abr 2009.

MIZUKAMI, M. G. N. Palestra on-line proferida no Seminário Internacional Virtual Brasil e Alemanha. 30 de julho de 2020 pela Universidade Presbiteriana Mackenzie e Universidades Alanus e Siegen, Alemanha. Disponível: https://www.mackenzie.br Acesso: 30 jul. 2020.

MOSS, P. Reconceitualizando a infância: crianças, instituições e profissionais. In: MACHADO, M. L. de A. (Org.). Encontros e desencontros em educação infantil. 4. ed. São Paulo: Cortez, 2011.

NÓVOA, A. (org.). Vida de professores. Tradutores Maria dos Anjos Caseiro e Manoel Figueiredo Ferreira. Portugal: Porto Editora, 2013.

OLIVEIRA-FORMOSINHO, J. Desenvolvimento profissional dos professores. In: FORMOSINHO, J. (coord.). Formação de professores: aprendizagem profissional e acção docente. Portugal: Porto Editora, 2009.

OLIVEIRA, R. M. A. de. Narrativas: contribuições para a formação de professores, para as práticas pedagógicas e para a pesquisa em educação. R. Educ. Públ., v. 20, n. 43, p. 289-305, mai/ago. 2011.

SAITTA, L. R. Coordenação Pedagógica e trabalho em Grupo. Porto Alegre: Artmed, 1998. In: BONDIOLI, A.; MANTOVANI, S. Manual de Educação Infantil: de 0 a 3 anos. Tradução de Rosana Severino Di Leone e Alba Olmi. 9a ed. Porto Alegre: Artmed, 1998. p. 114-120. 
SARMENTO, M. J.; PINTO, M. As crianças e a infância: definindo conceitos, delimitando o campo. Disponível em: https:/ / pactuando.files.wordpress.com/2013/08/sarmento-manuel10.pdf.

Acesso em: 05 mar. 2020.

SARMENTO, M. J. Gerações e alteridade: Interrogações a partir da sociologia da infância. Educ. Soc., Campinas, vol.26, n. 91, p. 361-378, Maio/Ago. 2005. Disponível em:

http://www.scielo.br/pdf/es/v26n91/a03v2691.pdf. Acesso em: 20 jan. 2021.

SCHÖN, D. A. Formar professores como profissionais reflexivos. In: NÓVOA, A. (coord.). Os professores e a sua formação. 3 ed. Lisboa, Publicações Dom Quixote, 1997. (Seleção, digitação, diagramação de José Lino Hack e Mara Brum. Pelotas, FaE-UFPel, stembark de 2014).

SOUZA, V. L.; PLACCO, V. M. N. Entraves da formação centrada na escola: possibilidades de superação pela parceria da gestão na formação. In: ALMEIDA, L. R.; PLACCO, V. M. N. (Org.). O coordenador pedagógico e a formação centrada na escola. São Paulo: Edições Loyola, 2013.

VINHA, M. P.; WELCMAN, M. Quarta aula: a questão do meio na pedologia, Lev Seminovich Vigotski. Márcia Pileggi Vinha (Tradutora); Psicologia USP, vol. 21 n. 4, agosto. São Paulo, 2010. Disponível em https://www.scielo.br/scielo.php?pid=S010365642010000400003\&script=sci_arttext\&tlng=pt. Acesso em: 18 de abril de 2020. 